\title{
O RECONHECIMENTO NA OBRA DE NORBERT ELIAS
}

\author{
RECOGNITION IN THE WORK OF NORBERT ELIAS
}

\author{
Sergio Baptista dos Santos ${ }^{1}$
}

\begin{abstract}
RESUMO
A produção teórica do sociólogo alemão Norbert Elias (1897 - 1990) aborda a relação entre poder, comportamento, emoção e conhecimento na História. No entanto toda sua obra tem como pano de fundo o que chamou de processo civilizatório que é o objeto de sua obra mais importante: O Processo Civilizador (1994). Elias nunca usou em seus escritos o conceito de reconhecimento tal qual ele é concebido na atualmente nas Ciências Sociais. A teoria do reconhecimento tem como orientação normativa o combate ao preconceito e a discriminação de determinados grupos e indivíduos, tendo em vista que a negação do reconhecimento causa danos subjetivos, constituindo-se numa forma eficaz de opressão. Neste artigo, nosso objetivo é procurar mostrar como, na obra de Elias (1897 - 1990), a noção de reconhecimento social constitui-se como um elemento fundamental para construção da autoimagem dos indivíduos. Nesse sentido, procuramos evidenciar que os pressupostos e conclusões desse sociólogo são semelhantes ao arcabouço teórico de um dos principais autores que trabalham com essa categoria, o filósofo canadense Charles Taylor (1931). Para efeitos metodológicos, apresentamos o conceito de reconhecimento na obra de Charles Taylor. Posteriormente, demonstramos como esse conceito é fundamental na obra de Norbert Elias.
\end{abstract}

Palavras-chave: Reconhecimento; Elias; Taylor.

\begin{abstract}
German sociologist Norbert Elias (1897 - 1990) addressed the relationship between power, behavior, emotion, and knowledge in History. His work had as its backdrop what he called the civilizing process, which is the object of his most important work: The Civilizing Process (1994). Elias never used the concept of recognition in his writings as it is currently conceived in the Social Sciences. The Theory of Recognition has as normative orientation the fight against prejudice and discrimination of certain groups and individuals, considering that the deprivation of recognition causes subjective harm, constituting an effective form of oppression. In this article, our objective is to show how social recognition constitutes a fundamental element for constructing an individuals' self-image in Elias's work. In this sense, we seek to demonstrate that this sociologist's assumptions and conclusions are similar to the theoretical framework of one of the principal authors working with this category, the Canadian philosopher Charles Taylor (1931). For methodological purposes, we present the concept of recognition in the work of Charles Taylor. We also demonstrate how this concept is fundamental in the work of Norbert Elias.
\end{abstract}

Keywords: Recognition; Elias; Taylor.

\footnotetext{
${ }^{1}$ Atualmente é Professor de Sociologia na Fundação de Apoio à Escola Técnica do Estado do Rio de Janeiro e do Instituto de Educação Rangel Pestana. Doutor em Ciências Sociais pela Universidade do Estado do Rio de Janeiro. Mestre em Ciências Sociais pela Universidade do Estado do Rio de Janeiro. e-mail: serbats@ gmail.com
} 


\section{INTRODUÇÃO}

A produção teórica do sociólogo alemão Norbert Elias (1897 - 1990) aborda a relação entre poder, comportamento, emoção e conhecimento na História. No entanto toda sua obra tem como pano de fundo o que chamou de processo civilizatório que é o objeto de sua obra mais importante: O Processo Civilizador (1994).

Elias nunca usou em seus escritos o conceito de reconhecimento tal qual ele é concebido atualmente nas Ciências Sociais. A teoria do reconhecimento tem como orientação normativa o combate ao preconceito e a discriminação de determinados grupos e indivíduos, tendo em vista que a negação do reconhecimento causa danos subjetivos, constituindo-se numa forma eficaz de opressão.

Neste artigo, nosso objetivo é mostrar como a noção de reconhecimento social constitui-se como um elemento fundamental para construção da autoimagem dos indivíduos na obra de Norbert Elias (1897 - 1990). Nesse sentido, procuramos evidenciar que os pressupostos e conclusões desse sociólogo são semelhantes ao arcabouço teórico de um dos principais autores que trabalham com essa categoria, o filósofo canadense Charles Taylor (1931).

\section{A POLÍTICA DO RECONHECIMENTO}

As lutas por "redistribuição" tornaram-se paradigma clássico que norteou a noção por justiça social até o penúltimo quartel do século XX, quando começa a perder espaço nas agendas dos movimentos sociais para as lutas por reconhecimento ${ }^{2}$.

A recente hegemonia das demandas por reconhecimento foi se constituindo num contexto de crise do modelo fordista de acumulação capitalista que fez ressurgir discursos mais radicais a favor do mercado livre coincidindo e se apoiando na implosão dos regimes socialistas

\footnotetext{
${ }^{2}$ Questão controversa. O filósofo al/o Axel Honneth (1949), da terceira geração da escola de Frankfurt, descorda que a luta por redistribuição tenha perdido espaço para lutas por reconhecimento. Na verdade, elas são imbricadas. Ver: HONNETH, Axel. Luta por Reconhecimento. A gramática moral dos conflitos sociais. 2a ed. São Paulo: Editora 34, 2003.
} 


\section{Revista \\ Debates Insubmissos}

do Leste Europeu. Essa nova forma de justiça social não está baseada na reivindicação por políticas de distribuição mais justas de recursos e riquezas, mas sim pela exigência de reconhecimento de grupos minoritários e "subalternos."

Segundo Taylor (2000), um dos principais formuladores das reivindicações por reconhecimento, é constitutivo dessa política o nexo entre reconhecimento e identidade. Para Taylor (2000), a identidade designa algo como a compreensão de quem somos, de nossas características definidoras fundamentais como seres humanos.

De acordo com esse autor, tais características definidoras resultam de uma construção dialógica, que se molda pelo reconhecimento ou por sua falta. A identidade de um indivíduo ou grupo pode sofrer graves danos se as pessoas, ou a sociedade, a refletem num quadro depreciável. A falta de reconhecimento constitui uma forma de opressão que aprisiona indivíduos ou grupos em um modo de ser falso e deformado.

Segundo Taylor (2000), tal forma de opressão se mostra tão eficaz que mesmo quando se extinguem os obstáculos objetivos à libertação de um grupo, seus membros são incapazes de aproveitar as novas chances devido à baixa autoestima provocada pela incorporação de imagens autodepreciativas que lhes foram atribuídas.

Um exemplo ilustrativo nesse sentido, segundo Taylor (2000), são as mulheres de sociedades patriarcais que foram induzidas a adotar uma imagem depreciativa de si mesmas. A internalização dessas imagens provocava-lhes perda de estima por si próprias e, por isso, sendo incapazes de aproveitar as oportunidades surgidas com a supressão dos obstáculos objetivos de sua opressão.

Esse discurso do reconhecimento e da identidade nem sempre foi familiar. Duas mudanças foram fundamentais, segundo Taylor (2000), para a preocupação atual com o reconhecimento e a identidade. A primeira ocorreu com fim do Antigo Regime e o consequente desmoronamento das hierarquias sociais que se baseavam na noção de honra. Essa noção no Ancien Regime, que marcava as distinções entre estratos sociais, é substituída pela noção de dignidade com um sentido universal e igualitário. O conceito de dignidade com tais 


\section{Revista \\ Debates Insubmissos}

características torna-se possível graças à sociedade democrática que emerge das ruínas do Antigo Regime "A democracia introduziu uma política de reconhecimento igual que assumiu várias formas ao longo dos anos e que agora voltou na forma de exigências de igual status de culturas e gêneros" (TAYLOR, 2000, p.243).

A segunda mudança que intensificou a importância do reconhecimento foi a nova compreensão de que a identidade individual passou a ter a partir do século XVIII, "[...] uma identidade individualizada, identidade particular a mim e que descubro em mim mesmo" (TAYLOR, 2000, p.243). É característico dessa nova compreensão um ideal de autenticidade que pressupõe que os indivíduos devem ser fieis a si mesmos.

Esse ideal de autenticidade emerge rompendo com a noção que os seres humanos são dotados de um sentido moral acerca do que é certo ou errado. Nessa concepção, estar em contato com a voz interior significava um meio de agir de modo certo. A mudança em relação a essa noção, segundo Taylor (2000), emerge com a necessidade de os seres humanos estarem em contato com os próprios sentimentos que assumem um caráter moral crucial e independente. Não se compreende a necessidade de ouvir a voz interna como um meio para agir de modo correto, mas para constituição de seres plenos.

Não há nessa nova concepção nenhuma fonte moral a que os homens devem vincularse, como Deus ou a Ideia do Bem para a plenitude enquanto seres humanos. A fonte desse ideal de autenticidade está dentro dos próprios seres humanos. Segundo Taylor (2000), essa é a mudança subjetiva fundamental do mundo moderno, “[...] uma nova forma de interioridade em que passamos a pensar-nos a nós mesmos como seres dotados de profundidades interiores" (TAYLOR, 2000, p.244).

Taylor (2000) aponta Jean-Jacques Rousseau como o pensador que proporcionou uma grande contribuição a essa virada subjetiva. Não foi um pioneiro, mas foi capaz de sistematizar um processo que já estava em curso na cultura. Para Rousseau, segundo Taylor (2000), a nossa redenção moral se resolve seguindo a nossa voz interna que muitas vezes é abafada pela vida em sociedade: 


\section{Revista \\ Debates Insubmissos}

Nossa salvação moral vem da recuperação do contato moral autêntico com nosso próprio ser. Rousseau até dá um nome a esse contato íntimo, mais fundamental do que qualquer visão moral, que é a fonte de tanta alegria e contentamento: Le sentiment de l'existence (TAYLOR, 2000, p. 244).

O desenvolvimento desse ideal de autenticidade, segundo Taylor (2000) tem seu desenvolvimento mais consequente por meio da filosofia de Johann Gottfried von Herder (1744 - 1803), para quem cada um de nós tem sua maneira própria de ser humano e o sentido de cada existência consiste em ser fiel a si mesmo. O que implica em que não devemos moldar nossa vida segundo pressões externas e também não devemos encontrar o modelo fora de nós. Assim procedendo cada indivíduo realiza uma potencialidade pré-existente que o faz singular.

De acordo com Taylor (2000), assim como a noção de dignidade, esse ideal de autenticidade foi resultado do declínio das sociedades aristocráticas. Nessa sociedade nossas características definidoras eram derivadas da posição que cada indivíduo ocupava na hierarquia social.

Nas sociedades democráticas, o ideal de autenticidade atribui a cada ser humano, não mais uma identidade derivada da estrutura social, mas a responsabilidade de descobri-la consigo mesmo. O que antes era atribuição externa passa a ser gerado internamente.

Segundo Taylor (2000), a procura de um eu gerado internamente é um ideal monológico que não contribui para compreensão entre reconhecimento e identidade. Tal vínculo só pode ser compreendido se levarmos em conta a natureza dialógica da construção das identidades. Taylor (2000) afirma que só nos tornamos agentes plenos, capazes de definir nossas identidades a partir das linguagens humanas. O termo linguagem é usado por esse autor num sentido mais amplo que a língua, engloba as linguagens da arte, gesto, amor etc. As pessoas, pare ele, contrariando o ideal monológico, não adquirem as linguagens para sua autodefinição a partir de um desenvolvimento interno independente das relações sociais com as pessoas que são significativas para nós.

Taylor (1995) define essas pessoas utilizando uma expressão cunhada pelo filósofo americano George Herbert Mead (1863-1931), "outros significativos.” 


\section{Revista \\ Debates Insubmissos}

Dessa forma, a construção da identidade não é um processo finito, mas um processo contínuo. Definimo-las no diálogo com as coisas que nossos “outros significantes” desejem ver em nós e, em certos casos, contra essas coisas. E mesmo que a contribuição dos "outros significantes" seja no começo de nossas vidas, como nossos pais, o diálogo com esses continua dentro de nós por toda nossa vida. Portanto, conclui Taylor (2000), a construção da identidade individual não pode ser realizada no isolamento, mas negociada por meio do diálogo com os “outros significantes". A compreensão dessa natureza dialógica de nossa identidade pessoal define a importância crucial que o reconhecimento tem para esse processo.

Enquanto nas sociedades hierarquizadas o reconhecimento estava embutido nas identidades derivados da estrutura social, na modernidade os indivíduos não gozam a priori desse reconhecimento. Eles têm que buscá-lo. O que se tornou uma questão crucial para a vida subjetiva à medida que o reconhecimento se é conseguido por meio do intercâmbio bem sucedido. Por outro lado, quando esse intercâmbio é mal sucedido, pode malograr.

Segundo Taylor (2000), hoje a necessidade de reconhecimento é universalmente compreendida como fundamental para construção de identidades. Na esfera íntima, a construção da autoidentidade pode ser bem ou mal sucedida de acordo com os nossos contatos com os "outros significantes".

Na esfera pública a compreensão que o devido reconhecimento é fundamental para a construção da identidade de determinados grupos sociais fez com que a busca normativa por reconhecimento se torna elemento mobilizador de uma série de movimentos sociais para os quais a justiça social não se realiza apenas com a redistribuição de riquezas, mas por meio do devido e apropriado reconhecimento:

O reconhecimento igual não é somente a modalidade apropriada a uma sociedade democrática saudável. Sua recusa pode, de acordo com uma disseminada visão moderna, como indiquei no começo, infligir danos àqueles a quem é negado. A projeção de uma imagem inferior ou desprezível sobre outra pessoa pode na verdade distorcer e oprimir na medida em que a imagem é internalizada. Não só o feminismo contemporâneo, mas também as relações entre raças e as discussões do multiculturalismo são movidos pela premissa de que negar reconhecimento pode ser uma forma de opressão (TAYLOR, 2000, p. 249). 
Debates Insubmissos

\section{CIVILIZAÇÃO E RECONHECIMENTO}

Nas sociedades desenvolvidas e altamente individualizadas, as pessoas, segundo Elias (1994), tendem a formar sua autoimagem como sendo isoladas e possuidoras de um mundo interno cuja formação, características e desenvolvimento independem das relações sociais, “[...] nômadas sem janelas, 'sujeitos' isolados, em relação aos quais o mundo inteiro, incluindo as outras pessoas, representa um 'mundo externo" (ELIAS, 2001, p. 61).

De acordo com Elias (1994), essa forma de representar-se expressa a autoconsciência de pessoas que foram obrigadas a adotar um grau elevado de refreamento dos instintos devido ao processo civilizador.

\subsection{O processo civilizador e autoconsciência}

Um dos elementos constitutivos do processo civilizador, segundo Elias (1996), é o crescimento das unidades de subsistência humana. De pequenos grupos consanguíneos que viviam em cavernas resultaram, com o curso do tempo, Estados nacionais que compreendem muitos milhões de pessoas.

Com a formação desses Estados, as funções relativas ao controle e proteção dos indivíduos previamente exercida por pequenos grupos foi sendo progressivamente absorvidas pelos Estados nascentes. Nessas sociedades estatais, centralizadas, urbanizadas e de alta diferenciação funcional, as relações sociais tornam-se racionalizadas e psicologizadas. Diferentemente dos antigos grupos, baseados na consanguinidade, onde as pessoas eram aceitas de forma incondicional, a integração dos indivíduos a grupos de seu interesse se dá por meio de seus esforços psicológicos de autocontrole de seus afetos, de negação dos instintos, de esconder dos outros suas funções corporais e controlar as manifestações de desejos agressivos que eram expressos livremente.

Num primeiro momento, o processo civilizatório ocorre por meio de esforços racionais dos indivíduos para manterem o autocontrole, mas, com passar dos anos e das gerações sai do nível de uma atividade consciente, o autocontrole é instilado tão profundamente pelos seres humanos que passa a constituir-se como “...uma segunda natureza” (ELIAS, 1994). 


\section{Revista \\ Debates Insubmissos}

Tal processo vai construindo uma diferenciação e tensão entre as proibições sociais inculcadas como autocontrole e os instintos recalcados dentro do ser humano. A progressiva exclusão de certas esferas de vida da interação social pelo medo socialmente instilado leva o indivíduo a pensar-se como possuidor de um mundo interno, isolado, sem relacionamento com os outros.

Mas, observa Elias (1994), tal forma de construção da autoimagem é inadequada para compreender a verdadeira relação entre indivíduo e sociedade. Na verdade, esse mundo interno não existe sem relação com os outros, o mundo externo. Um ser humano fora da existência prévia de pessoas relacionadas, caso sobrevivesse, seu desenvolvimento físico não corresponderia a seu desenvolvimento mental. Esse último estagnaria ao nível de um recémnascido. Sequer teria consciência de si.

A autoconsciência só é possível na interação com os outros. Não há para Elias (1994) contradição entre individualidade e interação social. O indivíduo, suas características mais íntimas e singulares, é resultado, não de um desenvolvimento interno de potencialidades préexistentes, mas do tipo da relação dialógica que estabelece com outros.

\subsection{Sentido e o reconhecimento}

À medida que o indivíduo não é um homo clausus, segundo Elias (2001), cujo self surge a partir de um desenvolvimento interno, como órgãos do corpo, constituído independente do mundo à sua volta, as tentativas de descobrir um sentido na vida não pode ser independente do que essa vida significa para as outras pessoas.

O "sentido" é uma categoria social, afirma esse autor, construído coletivamente por pessoas mutuamente dependentes e que podem comunicar-se entre si. Em suas relações, os símbolos que os integrantes dos grupos partilham assumem um sentido coletivo como a língua de uma mesma comunidade, por exemplo. Na comunicação por meio da língua, os padrões sonoros produzidos por uma pessoa só podem ter um sentido para as outras porque o emissor e receptor aprenderam a associá-los a imagens memorizadas. "Nessa forma, mais elementar de 'sentido', seu caráter social se mostra claramente” (ELIAS, 2001, p.64). Os sons só têm sentido 
para as pessoas que participam do mesmo contexto social onde aprenderam a usar, desde muito cedo, para se comunicarem, um código de símbolos específicos do grupo, a língua.

Assim como as palavras parece ser a vida de uma pessoa. De acordo com Elias (2001), o sentido da vida que uma pessoa assume para si não está separado do associado a ela pelas outras pessoas. Portanto:

A tentativa de descobrir na vida de alguém um sentido independente do que essa vida significa para os outros é inútil. Na práxis da vida social a conexão entre os sentimentos de uma pessoa e a consciência de que eles são significativos para os outros seres humanos, e de que os outros são significativos para essa vida, é fácil descobrir. Nesse plano, normalmente compreendemos sem dificuldade que expressões como significativas e insignificantes, referidas a uma vida, estão intimamente ligadas ao que significa para o outros o que essa pessoa é ou faz (ELIAS, 2001. p. 65).

No trecho acima, Elias (2001) mostra como o reconhecimento, ou, em outras palavras, a consciência de que os sentimentos de uma pessoa são significativos para os outros seres humanos, é crucial para a vida subjetiva dos indivíduos e sua falta pode ser trágico, o que fica muito explícito no livro em que autor escreve sobre a vida Mozart. Nesse trabalho, Elias (1995) atribui o fracasso desse músico a falta de reconhecimento que suportou, ou não suportou, durante período final de sua vida. Mozart não obteve o sucesso em Viena, que para ele era mais significativo do que em qualquer outro lugar, e perdeu o amor de sua esposa, suas duas mais significativas fontes de reconhecimento e autoestima. Essa foi sua tragédia:

Duas fontes de sua determinação de viver, dois mananciais que alimentavam sua fonte de autoestima e importância, estavam quase secos: o amor de uma mulher a quem pudesse confiar, e o amor do público vienense por sua música. Por algum tempo ele gozara de ambos; e ambos ocupavam um lugar mais alto na hierarquia de seus desejos. [...] Esta era sua tragédia- e a nossa - enquanto seres humanos (ELIAS, 1995, p. 9). 


\subsection{O reconhecimento em Winston Parva}

Na obra escrita em conjunto com John L. Scotson, "Os estabelecidos e Outsiders" (2000), esses autores mostram como o reconhecimento constitui-se em um mecanismo fundamental para a manutenção de determinadas relações sociais onde o diferencial de poder dos grupos sedimenta a configuração entre estabelecidos e outsiders.

O livro foi escrito após uma etnografia na cidade Winston Parva ${ }^{3}$. Uma comunidade que, a princípio, parecia ter uma constituição social homogênea da perspectiva étnica, classista, econômica, linguística, religiosa e de qualquer elemento objetivamente visível. Todavia, nas práticas sociais de seus moradores, encontrava-se nitidamente dividida entre dois grupos. Um grupo de moradores de longa data, os estabelecidos, e um grupo mais novo, os outsiders ${ }^{4}$.

O elemento diferencial entre esses grupos era o tempo de residência no local que conferia aos moradores mais antigos, por si só, um grau de coesão e identidade capazes de produzir nesses indivíduos à sensação gratificante de integrarem um grupo que se definia como humanamente superior aos recém chegados. Portanto, a superioridade dos estabelecidos era constituída pela coesão dos indivíduos que se conheciam a gerações, em oposição aos novos moradores que eram estranhos não apenas para os antigos, mas também entre si. Devido essa coesão os estabelecidos conseguiam reserva para si os melhores cargos das organizações locais e excluir os forasteiros 5 .

De acordo com Elias e Scotson (2000), a exclusão e estigmatização constituem mecanismos fundamentais para os estabelecidos preservarem sua identidade e confirmar, no plano objetivo, sua superioridade, mantendo o grupo outsiders no seu devido lugar: o de fora.

\footnotetext{
${ }^{3}$ Cidade de nome fictício localizada na periferia urbana da Inglaterra.

${ }^{4}$ Segundo Elias e Scotson (2000), Winston Parva, apresenta uma configuração social, em menor escala, e particularmente pura, um tema humano universal, uma configuração de poder desigual entre dois grupos interdependentes que pode ser observada em muitos outros contextos sociais

${ }^{5}$ Nessa pequena cidade podia-se ver como são limitadas algumas teorias, segundo Elias e Scotson (2000), que tentam explicar relações de poder com base somente na monopolização de bens econômicos e/ou bélicos por um grupo, sem levar em conta o poder que se originar da capacidade organizacional dos indivíduos. Em Winston Parva, em grande medida, o poder de um grupo sobre outro, não tinha base econômico nem na força física.
} 


\section{Revista \\ Debates Insubmissos}

Segundo Elias e Scotson (2000) para se entender a mecânica da estigmatização, é necessário compreender a função da imagem que cada indivíduo faz de seu grupo e seu status como membro desse grupo. Devido à configuração de poder favorável, os estabelecidos atribuem a si, como coletividades, e também individualmente a seus membros, suas características de pertencerem a um grupo humano superior. Entretanto, para beneficiarem-se dessas características, o indivíduo deve obedecer às normas de comportamento do grupo, sujeitando-se a padrões específicos de controle dos seus afetos. Todos os membros dos estabelecidos estão sujeitos a perder a estima e benefícios do grupo se mantiverem algum tipo de relação com os outsiders.

Tal controle torna-se possível, nesse tipo de configuração quando um grupo estabelecido reserva para si o acesso recompensador a instrumentos de poder e carisma, o que faz com que seus integrantes observem as normas coletivas. A não observação das regras pode trazer sérios danos a quem infringi-la: a perda de acesso a benefícios do poder e a estima do grupo, tal qual a sofrida pelos outsiders.

Portanto, o reconhecimento pela opinião do grupo, requer submissão estrita às regras estabelecidas $^{6}$. E ao não obedecer às regras, o indivíduo perde reconhecimento apropriado de seu grupo, o que traz, por sua vez, sérios danos a sua autoimagem.

A opinião do grupal tem, sobre certos aspectos tem o caráter da consciência da própria pessoa. Esta, na verdade, sendo formada num processo grupal, permanece ligada àquela por um cordão elástico, ainda que invisível [...] A autoimagem e autoestima dos indivíduos de um grupo estão ligadas ao que as outras pessoas do grupo pensam dele (ELIAS; SCOTSON, 2000, p. 40).

Por outro lado, os outsiders são vistos como não observantes dessas normas e padrões, por isso a imagem de anômicos é constituída em relação a eles. Numa configuração de desequilíbrio de poder, que sedimenta uma relação entre estabelecidos e outsiders, os grupos

\footnotetext{
${ }^{6}$ Em Winston Parva, Elias e Scotson (2000) relatam que durante o tempo da pesquisa não ouviram falar de casos de que algum membro dos estabelecidos houvera infringido regras de comportamento. Esses autores atribuem esse fato ao poder de coesão grupal exercer controle sobre seus membros, como força reguladora de seus sentimentos e conduta.
} 


\section{Revista \\ Debates Insubmissos}

mais poderosos impõem sua imagem deturpada e degradante sobre aos menos poderosos e são aceitas por esses como sua verdadeira natureza.

Essas representações, características constantes na relação entre estabelecidos e outsiders, observada em Winston Parva, são construídas pela capacidade do grupo mais poderoso de atribuir ao grupo "inferior" características negativas de sua porção "pior”, uma minoria anômica. Ou seja, constroem uma visão generalizante a partir de elementos presentes em pequenas partes do conjunto.

A construção da autoimagem dos estabelecidos tende a seguir um caminho contrário. Suas autorrepresentações são elaboradas a partir de seus melhores segmentos, e pensam-se como se todos os integrantes de seu grupo fossem portadores de tais características. Por meio dessas generalizações, os estabelecidos procuram provar suas afirmações sobre si e sobre os outsiders.

A possibilidade de imagens estigmatizantes serem produzidas pelos estabelecidos e tomadas como suas pelos outsiders estão inscritas num tipo de configuração específica que os grupos formavam em suas relações entre si. De acordo com Elias e Scotson (2000), a especificidade dessa configuração é o desequilíbrio de poder que constitui a pré-condição de qualquer estigmatização eficaz de um grupo estabelecido e sobre o grupo dos outsiders.

Nessa situação, a imagem generalizante e depreciadora produzida pelo grupo de maior poder sobre o de menor poder, tende a ser internalizada por esse último fazendo com que se sintam incapazes de reagir. Dito de outra forma, por conta das características específicas dessa configuração, quando o grupo de maior poder reconhece o grupo de menor poder por meio de uma imagem falsa e depreciadora, estas imagens, devido ao desequilíbrio de força em favor dos estabelecidos, tende a ser internalizado pelos outsiders. Nesse caso, a falta de reconhecimento apropriado torna-se uma forma de opressão que aprisiona os outsiders em um modo de ser falso e deformado. A situação só pode ser invertida caso haja alteração no quadro de forças.

Dessa forma, tomando a Winston Parva como um modelo de explicação para todas as figurações de estabelecidos e outsiders, Elias e Scotson (2000), mostram como o 
reconhecimento ou sua falta é fundamental para criação e manutenção dessas relações de força entre grupos interdependentes. Assim sendo, o reconhecimento exerce dois papéis: o primeiro, a busca de reconhecimento pelos integrantes do grupo dos estabelecidos os fazem observar os padrões de conduta de seu grupo, um elemento fundamental para a manutenção de sua coesão. E, segundo o reconhecimento negativo dos outsiders pelos estabelecidos por meio de imagens depreciadoras, constitui o elemento de manutenção de seu poder sobre o grupo de menor poder. Pois, à medida que essas imagens são internalizadas, provocam perda de autoestima e a consequente incapacidade de tentar mudar o quadro de relação de poder adversa.

\section{CONCLUSÕES}

Ao longo deste trabalho, buscamos apresentar os pontos em comum entre o pensamento de Norbert Elias e as teorias do reconhecimento por meio da obra de Charles Taylor. Para esse último, conforme discutido acima, as características definidoras de um indivíduo, não resultam de um desenvolvimento monológico, mas dialógico. Tal pressuposto também é partilhado por Norbert Elias. O que Taylor (2000) considera como desenvolvimento monológico, seria para Elias (1994), a concepção equivocada que o indivíduo tem de si como possuidor de um "eu” que se constrói independente das relações sociais. Ambos concordam que a imagem que o indivíduo atribui a si, suas características definidoras, se constrói num processo dialógico, ou seja, na interação social.

Ao concordarem com esse pressuposto, chegam a conclusões semelhantes quanto à importância do reconhecimento no processo de construção do self dos indivíduos. Para ambos, no processo constituinte da autoimagem dos indivíduos não é o reconhecimento de qualquer pessoa que tem significado. Segundo Elias (2006), são significativas aquelas pessoas que participam do mesmo contexto social e partilharam desde muito cedo os símbolos específicos do grupo. Taylor (2000) define essas pessoas utilizando uma expressão “outros significativos."

Para esses autores, o reconhecimento apropriado ou sua falta por esses "outros significativos" causa sérios danos ao sentido da vida dos indivíduos. Elias (1995) mostra isso em seu trabalho sobre Mozart, quando atribui seu sentimento de fracasso ao fato de não ter 
obtido o reconhecimento das pessoas que mais lhes importavam, seus "outros significativos", então, como escreveu, “[...] Esta era sua tragédia...” Elias (1995). Entretanto, para esse autor, a tragédia que apressou o fim da vida de Mozart, a falta de reconhecimento, é uma tragédia a que todos nós estamos suscetíveis, pois ela é "[...] a nossa - enquanto seres humanos [...]”. Ou seja, a falta de reconhecimento de seus "outros significados" é a tragédia para o sentido da vida de qualquer ser humano na civilização.

Além de tragédia individual, tanto para Elias (2000) quando para Taylor (2000), a falta de reconhecimento constitui uma forma de opressão. A autoimagem de um indivíduo ou grupo pode sofrer danos se as pessoas, ou a sociedade, a refletem num quadro depreciado. A ausência de reconhecimento apropriado constitui uma forma de opressão que aprisiona indivíduos ou grupos em um modo de ser deformado. O que pode ser observado na configuração estabelecidos e outsiders, em que Elias \& Escotson (2000) mostram como o grupo de menor poder incorporava as imagens que lhes eram atribuídas pelo grupo de maior poder, o que causava um efeito desmobilizador nos outsiders, contribuindo, desse modo, para manutenção da correlação de forças favorável aos estabelecidos.

\section{REFERÊNCIAS}

HONNETH, Axel. Luta por Reconhecimento. A gramática moral dos conflitos sociais. São Paulo: Editora 34, 2003.

ELIAS, Norbert. Escritos \& Ensaios 1. Rio de Janeiro: Jorge Zahar. 2006.

ELIAS, Norbert. A Solidão dos Moribundos. Rio de Janeiro: Jorge Zahar, 2001.

ELIAS, Norbert \& SCOTSON, John L. Os Estabelecidos e os Outsiders. Rio de Janeiro: Jorge Zahar. 2000.

ELIAS, Norbert. A sociedade dos indivíduos. Rio de Janeiro: Jorge Zahar.1994.

ELIAS, Norbert. Mozart: sociologia de um gênio. Rio de Janeiro: Jorge Zahar. 1995. 
ELIAS, Norbert. O processo civilizador: uma história dos costumes. Rio de Janeiro: Jorge Zahar, 1994.

ELIAS, Norbert. O processo civilizador: formação do estado e civilização. Rio de Janeiro: Jorge Zahar, 1994.

MEAD, George Herbet. Mind, self and society: from the standpoint of a social behaviorism. Chicago: The University of Chicago Press, 1934.

ROUSSEAU, Jean-Jacques. Discurso sobre a origem e os fundamentos da desigualdade entre os homens. São Paulo: Martins Fontes, 1999.

TAYLOR, Charles. A política do reconhecimento. In: Argumentos filosóficos. São Paulo: Edições Loyola, 2000.

Recebido: 06/03/2021

Aprovado: 16/05/2021 